\title{
Educação a Distância na Universidade de Passo Fundo: um relato de experiência
}

\author{
Ana Carolina Bertoletti De Marchi - UPF Virtual/UPF - carolina@upf.br \\ Isléia Rossler Streit - UPF Virtual/UPF - istreit@upf.br \\ Daniela De David Araújo - UPF Virtual/UPF - david@upf.br
}

\begin{abstract}
Resumo. A Educação a Distância (EaD) é uma modalidade de ensino que se constitui, entre outras possibilidades, como uma alternativa que viabiliza a formação continuada, oportunizando a atualização profissional e ampliando o acesso da população à educação superior brasileira. Destaca-se por suas peculiaridades inerentes à inserção, de forma massiva, das Tecnologias de Comunicação e Informação no processo de aprendizagem. Dessa forma, em número crescente, instituições de ensino superior estão somando tal modalidade à tradição do ensino presencial. Neste sentido, este artigo apresenta a experiência da Universidade de Passo Fundo no que se refere à trajetória percorrida, ao longo dos últimos quatro anos, para a implantação de ações de Educação a Distância entre suas atividades. O relato descreve o significado da EaD para a instituição, as principais políticas construídas, a importância da implantação dos $20 \%$ de semipresencialidade para a sensibilização do corpo docente e as ações para a consolidação de seu credenciamento para a área.
\end{abstract}

Palavras-chave: Educação a Distância, formação docente e semipresencialidade.

\section{Distance Learning at University of Passo Fundo: the report of an experience}

Abstract. Distance Learning is an educational modality which represents, among other possibilities, an alternative for continuous formation, allowing professional updating and the population access to superior education in Brazil. It stands out for its peculiarities related to the massively insertion of the Information and Communication Technologies into the learning process. Therefore, an increasing number of higher education institutions are adding such modality to their tradition of presential courses. This paper presents the experience of the University of Passo Fundo for the implementation of Distance Learning actions among its activities, considering the trajectory carried out during the last four years. The report describes the meaning of Distance Learning for the university; the main policies and guidelines organized; the importance of the semipresential teaching modality for the professors' awareness to the characteristics of the area and the actions accomplished aiming the institution's certification for Distance Learning.

Keywords: Distance Learning, teacher training courses and semipresential teaching. 


\section{Introdução}

A Universidade de Passo Fundo (UPF), situada na cidade de Passo Fundo (RS) a 300 $\mathrm{km}$ de Porto Alegre, possui mais de 40 anos de tradição em ensino superior de graduação e pós-graduação. Seus atuais 56 cursos de graduação abrangem mais de 100 cidades na região norte do estado.

Uma instituição comunitária como a UPF, que possui compromisso histórico com o crescimento econômico e com o desenvolvimento social da sua região, deve estar em constante processo de atualização, com condições de acompanhar as inovações nas diferentes áreas do conhecimento, especialmente no campo da educação - seu foco específico de atuação. Diante desse contexto, a Educação a Distância (EaD) destaca-se como uma proposta importante, notadamente por suas peculiaridades inerentes à inserção, de forma massiva, das Tecnologias de Comunicação e Informação (TICs) no processo de aprendizagem.

A EaD está se constituindo como uma alternativa de educação continuada, oportunizando atualização profissional e ampliando o acesso da população à educação superior brasileira. Barreiras de espaço e de tempo para a formação em nível de graduação e pós-graduação têm sido superadas com o desenvolvimento e a oferta de cursos em tal modalidade.

No cenário delineado, tornou-se evidente a importância estratégica do credenciamento da UPF para ofertar, cursos de graduação e pós-graduação na modalidade à distância. Entretanto, o encaminhamento do credenciamento institucional, para ser realizado de forma adequada e segura, requer a definição e a execução de um conjunto ações, entre elas: i) de planejamento técnico e pedagógico; ii) de formação/capacitação da equipe envolvida, corpo docente e tutores; iii) de gestão e iv) de sensibilização da comunidade acadêmica, incluindo setores de apoio técnico, administrativo e professores.

Assim sendo, este artigo apresenta o relato da experiência da Universidade de Passo Fundo no que se refere à trajetória percorrida, ao longo dos últimos quatro anos, para a implantação da modalidade de Educação a Distância na instituição, considerando os quatro pressupostos referenciados. Para tanto, inicia-se pela descrição de como a EaD é compreendida na UPF; avançando para suas principais políticas na área; e discutindo a importância da semipresencialidade para a sensibilização do corpo docente.

\section{Breve histórico e desenvolvimento da EaD na UPF}

As primeiras iniciativas relacionadas à Educação a Distância na UPF surgiram em 2001, com a criação de um setor denominado Centro de Educação a Distância (CEAD), hoje identificado como Divisão UPF Virtual. Do período que compreende sua criação até o ano de 2005, o CEAD atuou em atividades curriculares, fazendo uso de recursos e metodologias ligadas à área de $\mathrm{EaD}$ como complemento às ações presenciais em cursos de graduação e pós-graduação, além de capacitar docentes no uso de ambientes virtuais de aprendizagem que propiciassem aos alunos o cumprimento de atividades extraclasse.

No que se refere à capacitação docente, a primeira grande iniciativa foi a implementação de um curso de especialização lato sensu na instituição, em parceria com a Universidade Federal do Paraná. O curso "Especialização para a Formação de Professores para a Educação a Distância” ocorreu no período 2001-2002 e contou com a participação de vários docentes da UPF. 
Em 2005, atendendo à Portaria $\mathrm{n}^{0}$ 4.059, de 10 de dezembro de 2004, e procurando incentivar e regulamentar as disciplinas semipresenciais nos cursos de graduação reconhecidos da UPF, foi aprovada, pelo Conselho Universitário (CONSUN), a Resolução $\mathrm{n}^{0}$ 08/2005. A partir daquele momento, a modalidade semipresencial de ensino passou a ser vista como uma proposta em expansão na UPF, refletindo uma tendência na educação superior do país e uma aposta na ampliação das possibilidades de interação entre professores e alunos. A primeira disciplina semipresencial ofertada na instituição ocorreu no segundo semestre de 2007, no curso de Secretariado Executivo Bilíngue.

A continuidade dos estudos na área de $\mathrm{EaD}$ na instituição permitiu, além da oferta de cursos de extensão totalmente à distância, iniciativas inovadoras, como a definida nas Diretrizes Institucionais para Projetos Pedagógicos de Cursos de Graduação, anexo à Resolução CONSUN n ${ }^{0}$ 17/2007, que trata da previsão obrigatória de, no mínimo, uma disciplina semipresencial na matriz curricular de seus cursos de graduação reconhecidos, respeitando o limite de até 20\% (vinte por cento) da carga horária prevista para a integralização curricular.

Em paralelo, desde 2007, ações com vistas ao credenciamento da UPF junto ao MEC para a oferta de cursos de graduação e pós-graduação lato sensu à distância estão em andamento. Nesse sentido, internamento, a EaD é compreendida como mais uma oportunidade para ampliar sua atuação na comunidade regional e cumprir sua missão: "Produzir e difundir conhecimentos que promovam a melhoria da qualidade de vida e formar cidadãos competentes, com postura crítica, ética e humanista, preparados para atuar como agentes transformadores”.

A responsabilidade agregada à Educação a Distância para o cumprimento da missão institucional está fundamentada, principalmente, em seis princípios que fazem dessa modalidade de ensino uma fonte promissora para a formação de profissionais comprometidos com seu meio, a saber (SEAD/MEC 2007), (Maia e Mattar 2007), (Moore e Kearsley 2007) e (Filatro 2007):

a) interação e aprendizado colaborativo: permite a construção do conhecimento pelo viés do diálogo e da troca constante de saberes junto aos alunos e professores, que superam a distância física e temporal nas relações interpessoais, tendo em vista o compromisso assumido com o desenvolvimento intelectual, cultural e humano dos sujeitos envolvidos no processo educativo;

b) autonomia na aprendizagem: contribui para a formação de um sujeito comprometido com o estudo, responsável pela organização de seu tempo na busca contínua do aprender. O aluno à distância precisa assumir sua autonomia, envolvendo-se em uma rede de relacionamentos que favoreça o desenvolvimento cognitivo de todo o grupo;

c) flexibilização do tempo e do espaço: possibilita a realização das atividades em horário e local mais apropriado ao acadêmico, em especial àquele já inserido no mercado de trabalho, reduzindo as horas de deslocamento até a universidade e possibilitando o cumprimento das tarefas e o envolvimento no curso durante os sete dias da semana, de acordo com a necessidade e característica de cada aluno;

d) potencialização das ferramentas tecnológicas na educação: considera as Tecnologias de Informação e Comunicação a serviço do processo de ensinar e aprender à distância, fomentando a apropriação das mesmas em prol da formação 
humana e profissional, uma vez que o aluno incorpora tal instrumental ao seu cotidiano em busca do cumprimento dos objetivos do curso;

e) qualidade dos materiais e da metodologia: prevê um processo cuidadoso nas fases de planejamento, desenvolvimento, implantação e avaliação dos materiais a serem adotados nas disciplinas ou unidades curriculares dos cursos à distância, considerando, ainda, a realidade dos acadêmicos e o atendimento as suas necessidades;

f) apoio e suporte: mantém estrutura de apoio técnico e pedagógico ao acadêmico, objetivando a interação permanente com o estudante, o esclarecimento de suas dúvidas e o incentivo para a continuidade dos estudos, de forma a fortalecer o engajamento do aluno com o curso.

Pode-se observar, portanto, que, na UPF, a opção pelo envolvimento com EaD, após sua trajetória de mais de 40 anos em cursos presenciais, vem sendo paulatinamente construída junto à comunidade acadêmica. Pauta-se, para tanto, pela legislação específica em vigor ${ }^{1}$ e, ainda, pela observação dos referenciais de qualidade estabelecidos pelo MEC para cursos à distância (SEAD/MEC 2007). Tal documento compreende categorias que envolvem, fundamentalmente, aspectos pedagógicos, de recursos humanos e de infraestrutura, importantes para a implementação bem sucedida de experiências na área.

\section{Ações para a implantação da EaD na UPF}

Ao longo dos últimos quatro anos, o foco da instituição para a EaD priorizou: i) o fortalecimento do setor responsável pela EaD; ii) a consolidação do programa de formação/capacitação docente, discente e de tutores; iii) a difusão e o acompanhamento da oferta de disciplinas semipresenciais e iv) o credenciamento da instituição para EaD.

As ações realizadas com vistas a atingir tais objetivos também visam, indiretamente, à sensibilização do corpo docente quanto aos benefícios da inclusão de Tecnologias de Informação e Comunicação ao processo de aprendizagem e, ainda, à qualificação dos materiais didáticos utilizados em sala de aula, de modo a constituir um grupo de professores com experiência na modalidade à distância.

\subsection{Fortalecimento do setor EaD}

O fortalecimento do setor responsável pela EaD na UPF teve início com a sua reestruturação em 2007. O então Centro de Educação a Distância (CEAD) passou a se chamar Divisão UPF Virtual - com aprovação do regimento próprio pelo Conselho Universitário -, e localização privilegiada, em área central do campus universitário.

Embora esteja vinculada administrativamente à Vice-Reitoria de Graduação, a Divisão UPF Virtual tem autonomia para atuar e desenvolver projetos junto à ViceReitoria de Pesquisa e Pós-Graduação e à Vice-Reitoria de Extensão e Assuntos Comunitários, de acordo com as necessidades e/ou demandas de tais instâncias.

\footnotetext{
${ }^{1}$ Lei no 9.394 de 20/12/1996; Portaria MEC no 4.059 de 10/12/2004; Decreto ${ }^{0} 5.622$ de 19/12/2005; Portaria Normativa $n^{0} 2$ de 10/01/2007; Decreto n 6.303 e Portaria Normativa n 40 de 12/12/2007.
} 
A maior visibilidade alcançada pelo setor em decorrência do trabalho desenvolvido trouxe um aumento nas solicitações de serviços e, consequentemente, na consolidação de uma equipe multidisciplinar qualificada. Adicionalmente, para criar condições para o atendimento da demanda gerada com futuros cursos de graduação e pós-graduação à distância, foi necessário o investimento em infraestrutura de apoio condizente às práticas de atividades à distância.

Assim sendo, destacam-se como as principais ações realizadas para o fortalecimento do setor:

a) a capacitação permanentemente da equipe multidisciplinar para o desenvolvimento das atividades de EaD;

b) a otimização e a ampliação da infraestrutura tecnológica para EaD, através do estudo constante do ambiente virtual de aprendizagem Moodle - oficializado institucionalmente para dar suporte às atividades de interação entre professores e alunos afastados geograficamente -, bem como a aquisição de equipamentos para videoconferência e para a produção de material didático online.

c) a ampliação e a inserção de outras mídias, como TV e rádio, para apoio às atividades não-presenciais. Destacam-se os recursos já instalados na Rádio UPF e na UPF TV, além do estabelecimento de parcerias internas com diferentes setores para a qualificação do material produzido para as disciplinas semipresenciais e cursos à distância.

\subsection{Programa de Formação Continuada em EaD}

A Divisão UPF Virtual possui três projetos para capacitação dos docentes, tutores e corpo técnico-administrativo da instituição à EaD, além da proposta voltada aos discentes para a utilização do ambiente virtual de aprendizagem institucional. Nesta frente de trabalho são desenvolvidas práticas para ampliar a oferta de cursos de extensão à distância, com vistas a facilitar o acesso pela comunidade regional ao conhecimento produzido internamente, bem como atender às necessidades de mercado.

A) Formação docente:

Os cursos de formação docente em EaD são promovidos sistematicamente, já tendo capacitado vários professores da Universidade de Passo Fundo para atuarem em disciplinas semipresenciais ou à distância. Essas atividades são especialmente direcionadas aos envolvidos na área ou com interesse em tal iniciativa.

Desde 2007, diante: a) do pedido de credenciamento da instituição para EaD; b) da oferta de cursos de graduação reconhecidos que incluem em sua matriz curricular disciplinas semipresenciais e c) de professores que desenvolvem atividades de EaD complementares ao ensino presencial, a Divisão UPF Virtual elaborou seu programa de Formação Docente em EaD, que totaliza 100 horas de atividades, com os seguintes objetivos:

- iniciar os docentes da UPF nas discussões sobre Educação a Distância, abordando temas conceituais, históricos e de legislação relacionados à área; 
- discutir o planejamento de disciplinas semipresenciais ou de cursos à distância, abordando os estudos teóricos/pedagógicos a respeito, as etapas de elaboração do aprendizado online e a configuração do ambiente virtual de aprendizagem Moodle;

- acompanhar individualmente o professor, a partir da disciplina em desenvolvimento no Moodle, focalizando a configuração do material e a tutoria aos alunos;

- dar suporte aos professores da UPF na modalidade de ensino semipresencial e à distância;

- possibilitar e qualificar o contato dos professores da UPF com ferramentas de aprendizagem virtual e mídias diferenciadas para a produção dos materiais didáticos.

Do modo como está estruturada, a Formação Docente em EaD é composta por três módulos que podem ser cursados isoladamente: i) Módulo I - Fundamentos de Educação a Distância; ii) Módulo II - Planejamento de curso à distância e iii) Módulo III - Prática docente em EaD. Desenvolvido totalmente à distância, através do ambiente Moodle, o material didático inclui textos, animações, videoaulas, apresentações e tutoriais. As atividades solicitadas aos cursistas exigem interação, colaboração, estudo, pesquisa, síntese e produção.

Ao final de cada etapa, o professor com rendimento satisfatório dentro dos critérios de avaliação estabelecidos recebe um atestado de conclusão do módulo. Ao término dos três módulos, é emitido o certificado final de 100 horas, válido como comprovante de formação na área para atuar em disciplinas semipresenciais ou à distância na UPF. O programa do curso é elaborado e executado pela equipe da Divisão UPF Virtual, que presta suporte e tutoria aos cursistas, além de arquivar todos os documentos e registros de tais atividades.

B) Formação dos tutores:

O curso de formação de tutores proposto pela Divisão UPF Virtual é desenvolvido à distância em dois módulos, com 20 horas de atividades cada, através do ambiente Moodle. São objetivos do curso: a) apresentar as principais características da Educação a Distância no Brasil; b) identificar as diferentes atribuições dos sujeitos envolvidos na Educação a Distância; c) utilizar as ferramentas do ambiente virtual de aprendizagem Moodle; d) configurar atividades que oportunizem interação, interatividade e construção de conhecimento, em um ambiente virtual de aprendizagem.

Ao longo do curso são desenvolvidas atividades individuais e em grupo (estudos de caso, questões discursivas, fóruns de discussão e chats, além de tarefas práticas) que permitirão aos tutores construir os referencias básicos tanto quanto à EaD e à tutoria, como quanto às situações do contexto profissional prático do ensino online. 
C) Curso para alunos:

Diante da oferta de cursos de graduação que incluem em sua matriz curricular disciplinas semipresenciais, faz-se necessário que o aluno das referidas graduações - e de outras nas quais os professores desenvolvem atividades de $\mathrm{EaD}$ complementares ao ensino presencial -, tenha acesso a cursos de capacitação na ferramenta oficial adotada pela instituição (o Ambiente Virtual de Aprendizagem Moodle), para que as desenvolvam com aproveitamento. Trata-se de um curso de 20 horas, estruturado em quatro módulos desenvolvidos à distância através de atividades síncronas e assíncronas.

\subsection{As disciplinas semipresenciais}

A Universidade de Passo Fundo acredita que a utilização de até 20\% da carga horária dos cursos superiores presenciais reconhecidos à distância (ora mencionada como disciplinas semipresenciais) vem ao encontro dos interesses e das necessidades dos acadêmicos, uma vez que a utilização de métodos e de ferramentas vinculadas à EaD possibilita aos mesmos a aproximação e a apropriação no uso das Tecnologias de Informação e Comunicação (TICs). Além disso, qualifica a formação profissional por incentivar o espírito de investigação, a interação e a colaboração nas relações acadêmicas e na construção do conhecimento.

Assim como em cursos EaD, as disciplinas semipresenciais também flexibilizam o processo de aprendizagem em relação ao tempo, ao espaço e demandam uma atitude diferenciada do aluno frente aos estudos, no que diz respeito a sua organização e autonomia. Nessa perspectiva, a oferta de disciplinas semipresenciais num curso de graduação presencial pode ser de grande relevância, visto que possibilitam a complementação da formação do aluno pelo aprimoramento do perfil comportamental e das habilidades no uso de ferramentas tecnológicas importantes para o profissional contemporâneo (Bertolin e De Marchi 2009).

A modalidade semipresencial está respaldada: i) pela legislação em vigor; ii) pelas normatizações internas da UPF, tendo como base as Resoluções Consun № 8/2005 e Consun $\mathrm{N}^{\mathrm{0}}$ 17/2007 e iii) por políticas educacionais estabelecidas pela Divisão UPF Virtual, em consonância com outros setores da instituição. Igualmente, como forma de orientar coordenadores e colegiados, a Divisão UPF Virtual criou um guia que reúne informações importantes para a implantação e implementação das disciplinas semipresenciais nos cursos de graduação reconhecidos da UPF. Atualmente, no semestre 2010/1, há 31 disciplinas semipresenciais em andamento, envolvendo onze cursos de graduação e 24 professores.

A semipresencialidade possibilita que o professor enriqueça e amplie seu fazer pedagógico, implantando, dentre outras práticas, um sistema de qualificação permanente do material didático.

\subsection{O credenciamento para EaD}

As frentes de trabalho citadas e implementadas ao longo dos últimos quatro anos buscam atingir dois objetivos principais: 
a) ampliar na comunidade acadêmica, seja entre os docentes e os discentes, o conhecimento sobre a Educação à Distância, desenvolvendo um conjunto teórico e prático de informações que possam dar sustentabilidade e continuidade às políticas em tal modalidade;

b) formar um grupo de professores aptos a atuarem com comprometimento no suporte teórico e de práticas pedagógicas por ocasião do credenciamento da UPF para $\mathrm{EaD}$, com a autorização inicial de três polos de apoio presencial e do primeiro curso de graduação à distância.

A UPF considera fundamental investir na qualidade dos cursos à distância, seja através da definição de diretrizes e critérios para a elaboração de material didático, como também na qualificação dos polos de atendimento presencial e nos projetos pedagógicos dos cursos. O processo de credenciamento está em andamento, sendo que a instituição recebeu, no último mês, duas visitas de comissões de avaliação do MEC para a autorização dos polos e para o ato de credenciamento propriamente dito.

\section{Sistema de avaliação na EaD}

A avaliação dos processos educacionais é um tema complexo e que possui grande importância nas abordagens e projetos de qualidade de instituições, cursos e disciplinas da educação superior.

Quando abordada no âmbito da Educação a Distância, a avaliação da qualidade da educação adquire uma relevância e complexidade ainda maiores, visto que as diferenças de espaço e tempo entre professor e aluno certamente impactam o processo de aprendizagem.

A avaliação da qualidade da modalidade EaD na UPF foi consolidada por meio do desenvolvimento de um projeto de pesquisa que culminou na proposição de instrumentos para avaliação de disciplinas semipresenciais da educação superior. Fundamentado em sistemas de indicadores e composto por questionários de avaliação e auto-avaliação, o instrumento incorpora aspectos de auto-validação ao permitir o cotejamento entre os indicadores de resultados e os aspectos de entradas e processo da disciplina e entre a avaliação de um sujeito interessado e a auto-avaliação de outros sujeitos envolvidos (Bertolin e De Marchi 2009).

Neste sentido, foram desenvolvidos questionários específicos para os diferentes sujeitos com vistas a cobrir todos os aspectos (indicadores) a serem avaliados e possibilitar a auto-validação da própria avaliação.

\section{Considerações Finais}

Conforme o relato apresentado neste artigo, o processo de credenciamento para a EAD e de autorização de polos de apoio presencial da Universidade de Passo Fundo é fruto do trabalho conjunto de vários setores da instituição que vislumbraram tal modalidade nas suas discussões e possibilidades de ensino. Pode-se citar como exemplo:

(i) as ações da Vice-Reitoria de Graduação, através da Divisão de Ensino de Graduação, que fomentou a inserção da semipresencialidade nos projetos pedagógicos de todos os cursos presenciais de graduação reconhecidos. Tal decisão estratégica criou a demanda 
para a formação docente em EaD e para o uso das TICs em sala de aula, além do contato mais próximo e pontual com as discussões de EaD, suas teorias e metodologias na comunidade acadêmica;

(ii) as ações da Vice-Reitoria de Extensão e Assuntos Comunitários, que viabilizaram os projetos de extensão planejados e desenvolvidos - total ou parcialmente à distância para a comunidade regional;

(iii) as ações da Vice-Reitoria Administrativa que atenderam às solicitações de ampliação da infraestrutura técnica e tecnológica para a aquisição de equipamentos, viabilizando a realização de videoconferências e transmissões em âmbito interno e também externo.

(iv) a parceria estabelecida com os setores de Recursos Humanos, de Tecnologia da Informação, com a Rádio UPF e UPF TV, para o estabelecimento de políticas de pessoal e de uso de equipamentos para a construção de materiais didáticos.

Ao ponderar sobre o caminho percorrido até aqui, percebe-se que a inserção de tal modalidade em uma instituição de ensino com tradição presencial também significa o fomento de uma cultura de EaD no corpo docente, nos gestores e pesquisadores, que possibilite a associação e apropriação das teorias e das práticas de ensino a ela identificadas. Dessa forma, as ações de Educação a Distância implementadas na UPF pretendem criar o perfil docente e discente apto para ensinar e aprender com qualidade nesse desafiante cenário educacional ao qual estamos inseridos.

\section{Referências Bibliográficas}

Bertolin, Júlio César G. e De Marchi, Ana Carolina B. Uma Proposta de Indicadores para Avaliar a Qualidade de Disciplinas Semipresenciais em Cursos de Graduação. Revista Brasileira de Computação Aplicada. Vol.1, nro. 1, 2009.

Filatro, Andrea. Design instructional contextualizado - educação e tecnologia. São Paulo: Editora Senac São Paulo. 2007.

Maia, Carmem e Mattar, João. ABC da EaD. São Paulo: Pearson Prentice Hall. 2007.

Moore, Michael e Kearsley, Greg. Educação a Distância - uma visão integrada. São Paulo: Thomson Learning. 2007.

SEED/MEC. Referenciais de Qualidade para Educação Superior a Distância Versão Preliminar. Brasília, 2007. 